\title{
Associations between ECG changes and echocardiographic findings in patients with acute non-ST elevation myocardial infarction
}

\section{Tuohinen, Suvi Sirkku}

2018

Tuohinen , S S, Rankinen , J , Skyttä , T , Huhtala , H , Virtanen , V , Kellokumpu-Lehtinen , P-L , Raatikainen , P \& Nikus , K 2018 , ' Associations between ECG changes and echocardiographic findings in patients with acute non-ST elevation myocardial infarction ' , Journal of Electrocardiology, vol. 51 , no. 2 , pp. 188-194 . https://doi.org/10.1016/j.jelectrocard.2017.11.007

http://hdl.handle.net/10138/301305

https://doi.org/10.1016/j.jelectrocard.2017.11.007

publishedVersion

Downloaded from Helda, University of Helsinki institutional repository.

This is an electronic reprint of the original article.

This reprint may differ from the original in pagination and typographic detail.

Please cite the original version. 


\title{
Associations between ECG changes and echocardiographic findings in patients with acute non-ST elevation myocardial infarction is
}

\author{
Suvi Sirkku Tuohinen, MD, PhD ${ }^{\text {a,b,c,* }}$, Jani Rankinen, MS ${ }^{\text {b,c }}$, Tanja Skyttä, MD, PhD ${ }^{\text {b,d }}$, Heini Huhtala, MSc ${ }^{\text {e }}$ \\ Vesa Virtanen, MD, PhD ${ }^{\mathrm{b}, \mathrm{c}}$, Pirkko-Liisa Kellokumpu-Lehtinen, MD, PhD ${ }^{\mathrm{b}, \mathrm{d}}$, \\ Pekka Raatikainen, MD, PhD ${ }^{a}$, Kjell Nikus, MD, PhD ${ }^{\text {b,c }}$ \\ ${ }^{a}$ Heart and Lung Center, Helsinki University Central Hospital and Helsinki University \\ ${ }^{\mathrm{b}}$ Faculty of Medicine and Life Sciences, University of Tampere, Finland \\ ${ }^{\mathrm{c}}$ Heart Center, Tampere University Hospital, Finland \\ d Department of Oncology, Tampere University Hospital, Finland \\ e Faculty of Social Sciences, University of Tampere, Finland
}

\section{A R T I C L E I N F O}

\section{Keywords:}

Non-ST elevation infarction

ECG

Speckle tracking echocardiography

Integrated backscatter

\begin{abstract}
A B S T R A C T
Background: ST segment depression (STD) and T wave inversion (TWI) are typical electrocardiographic (ECG) findings in non-ST elevation myocardial infarction (NSTEMI). In ST elevation myocardial infarction, ST changes represent transmural ischemia. The pathophysiological mechanisms of the ECG changes in NSTEMI are unclear. Purpose: We studied the associations between ECG and the echocardiographic findings in NSTEMI patients. Methods: Twenty patients with acute NSTEMI were recruited during their hospital stay. A comprehensive echocardiography study was performed. The findings were compared with blinded ECG analyses.

Results: Nine (45\%) patients had STD, and 16 (85\%) patients had TWI. In multivariable analysis, STD was independently associated with a lower global early diastolic strain rate $(\beta=-5.061, p=0.033)$. TWI was independently associated with lower circumferential strain $(\beta=0.132, p=0.032)$.

Conclusions: The typical ECG changes in NSTEMI patients were associated with subtle echocardiographic changes. STD was related to changes in diastolic function, and TWI was associated with systolic deterioration.
\end{abstract}

(c) 2017 Elsevier Inc. All rights reserved.

\section{Introduction}

In ST elevation myocardial infarction (STEMI), acute coronary occlusion causes transmural myocardial ischemia, which is expressed as ST elevations and prominent positive $\mathrm{T}$ waves on the electrocardiogram (ECG). The location of the ST elevations on the ECG depends on the ischemic myocardial region [1]. On the other hand, non-ST elevation myocardial infarction (NSTEMI) is a heterogeneous clinical condition with a variable pathophysiological background. ST depression (STD) and T wave inversion (TWI) are the typical ECG changes in NSTEMI patients. STD is most often located in the lateral precordial leads, V4-V6, independent of the coronary anatomy [2-4]. "Wellens' syndrome" - TWI in precordial leads V1-V3/V4 caused by a lesion in the left anterior descending coronary artery (LAD) - is an example of the association between the location of TWI on the ECG and the culprit artery in acute coronary syndrome [4].

\footnotetext{
is Conflict of interest: None to declare.

* Corresponding author at: Heart and Lung Center, Helsinki University Central Hospital and Helsinki University, PO Box 340, 00029 Helsinki, Finland.

E-mail addresses: suvi.tuohinen@fimnet.fi, suvi.tuohinen@hus.fi (S.S. Tuohinen).
}

Echocardiography has a central role in the diagnosis and risk stratification of acute myocardial infarction (MI) patients [5]. Newer techniques, such as tissue Doppler imaging and speckle tracking echocardiography, have emerged as valuable diagnostic and prognostic tools in patients with acute coronary syndrome [6]. Their roles in the clinical evaluation of NSTEMI patients are being explored.

The goal of our study was to evaluate the relationships between ECG changes and concurrent echocardiographic findings in patients with acute NSTEMI. This comparison may shed some light on the mechanisms behind these ECG changes, which in turn potentially could improve risk stratification in acute coronary syndrome patients. We hypothesize that STD and TWI may differ with respect to their association with echocardiographic systolic and diastolic functional parameters.

\section{Materials and methods}

Patient selection

Patients were recruited at the Heart Center Tampere University Hospital from April 2012 to June 2015. Twenty NSTEMI patients without 
a history of cardiac disease were recruited after coronary angiography. The exclusion criteria were significant valvular stenosis or regurgitation (grade 2 or higher), prior MI, non-sinus rhythm, the presence of a pacemaker, wide QRS complex ( $120 \mathrm{~ms}$ ), and severe lung disease or other significant pathology, such as severe infection or pericardial effusion. The study protocol was approved by the local ethical committee (R11149) and each patient signed an informed consent form before enrollment in the study.

\section{Cardiac examinations}

All patients underwent coronary angiography during their hospital stay and repeated analyses of biomarkers and 12-lead ECG recordings were conducted according to the normal hospital protocol.

A 12-lead ECG was routinely recorded upon arrival to the hospital and repeated at least once during the hospital stay. The ECG closest to the time of the echocardiographic study was used in the analysis. A manual analysis of the ECG was performed with a magnifying lens by two authors (JR and KN) blinded to the clinical and echocardiographic data. The data were analyzed separately for three anatomic territories corresponding to the coronary artery distribution: anterior territory leads V1-V4 (LAD territory), inferior territory leads II, III and aVF (right coronary artery territory, RCA), and lateral territory leads I, aVL and V5-V6 (left circumflex artery territory, LCX), please see Fig. 1. The cut-off value for STD was $0.05 \mathrm{mV}$ at the J point. The corresponding value for TWI was $0.1 \mathrm{mV}$. Both STD and TWI had to be present in at least two contiguous leads (Fig. 2). Pathological Q waves were defined according to current guidelines [7].

Thorough echocardiography was performed within one ( 0 to 2 ) day after coronary angiography. Invasive procedures were performed according to the current national and international guidelines and this was also the case for anti-thrombotic and anti-ischemia medical therapy [8]. All echocardiographic examinations were performed with a commercially available cardiac ultrasound machine (Philips iE33 ultrasound system, Bothell, Washington, USA) and a 1-5 MHz matrixarray X5- 1 transducer by the same cardiologist (SST). All imaging was acquired at rest with the patients in the left lateral decubitus position. Doppler recordings were acquired at end-expiration. A simultaneous superimposed ECG was used throughout the studies. The images were stored in an external hard drive for off-line analysis (Philips Qlab, Bothell, Washington, USA). For the wall motion score analysis, the left ventricle was divided into 17 segments [9]. Each segment received a grade as follows: 1 - normal, 2 - hypokinesia, 3 - akinesia and 4 - dyskinesia. The total wall motion score was calculated by adding the score of each segment and the wall motion score index was obtained by dividing the total wall motion score by the number of left ventricular segments.

The analysis to compare the ECG and echocardiographic results was conducted in two ways. First, echocardiographic parameters reflecting global changes were compared with the presence of STD or TWI. Second, the left ventricle was divided into the three segments corresponding to the regions perfused by the LAD, RCA and LCX. The regional results reflecting these segments were compared with corresponding changes in the ECG (Fig. 1).

\section{Statistical analysis}

Data are reported as means and standard deviations for normally distributed variables and as medians with ranges for other continuous variables. Differences in baseline characteristics between the groups were tested with the independent samples Student's t-test for continuous variables and with Fisher's exact test for categorical variables. Differences between the groups were analyzed with independent

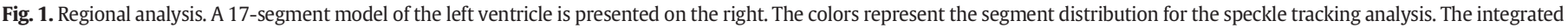

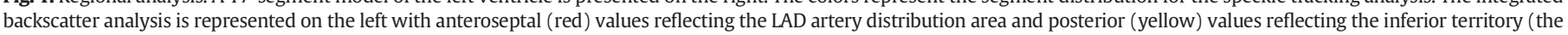
RCA distribution area). LAD = left anterior descending; RCA = right coronary artery; LCX = left circumflex; OM = obtuse marginal; $L D=$ left diagonal; IM = intermediate branch. 


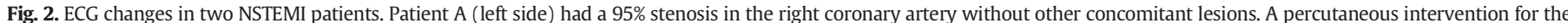

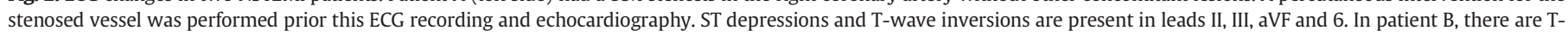

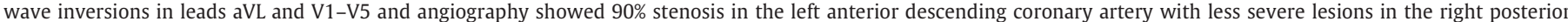

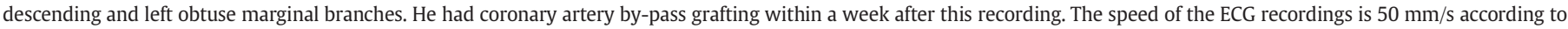
national standard.

samples t-tests for normally distributed variables or with the independent samples Mann Whitney U test for variables with skewed distribution and categorical variables were analyzed with the $\mathrm{X}^{2}$ /Fishers exact test. Associations between variables were calculated with Spearman correlations. A regression analysis was used to test univariate associations and a linear forward regression analysis was used to test multivariable associations. The tested variables are shown in Tables 3 and 4. Statistical analyses were carried out with IBM SPSS Statistics for Windows, Version 23.

\section{Results}

\section{General characteristics}

The patient population had a male predominance (80\%) with a mean age of $63 \pm 9$ years. For other baseline characteristics, please see Table 1 . The patient characteristics showed no significant differences across different ECG findings.

The median duration of angina pectoris prior to hospitalization was 2.5 days ( 0 to 21 days) and coronary angiography was performed within 1 day ( 0 to 2 days) of hospital admission. The echocardiographic examination was performed 1 day ( 0 to 6 days) after angiography. Coronary angiography revealed one-vessel disease in eight (40\%) patients, two-vessel disease in seven (35\%) patients and three-vessel disease in five $(25 \%)$ patients. None of the patients had left main coronary artery involvement. Three patients had a total occlusion (one proximal LCX, one mid-RCA and one distal RCA); none of these patients were considered "STEMI equivalent" based on the ECG findings. At the time of echocardiography, 14 (70\%) patients were treated with percutaneous coronary artery intervention (PCI) with stenting for their culprit lesion. The remaining patients had received medical treatment and four $(20 \%)$ patients were scheduled to undergo coronary artery by-pass surgery later on.

Regarding myocardial ischemia after invasive evaluations and therapy, 16 (27\%) of 60 segments had been treated successfully with PCI, 21
(35\%) segments had normal coronary flow, and 23 (38\%) segments were still supplied by coronary arteries with significant stenosis (diameter of stenosis 50\%). All patients were stable at the time of echocardiography and were either transferred to a local hospital or discharged from our hospital within 4 (1 to 20) days after hospital admission.

Table 1

Characteristics of the study population.

\begin{tabular}{lll}
\hline & \multicolumn{2}{l}{ The entire group } \\
\cline { 2 - 3 } & $\mathrm{n}=20$ \\
\cline { 2 - 3 } & Mean/median & $\mathrm{SD} /\left(\mathrm{Q}_{1}, \mathrm{Q}_{3}\right)$ \\
\hline Age (years) & 63.0 & 9.3 \\
Systolic blood pressure $(\mathrm{mm} \mathrm{Hg})$ & 131 & $(124,142)$ \\
Diastolic blood pressure $(\mathrm{mm} \mathrm{Hg})$ & 81 & $(68,89)$ \\
BMI $\left(\mathrm{kg} / \mathrm{m}^{2}\right)$ & 27.6 & $(24.5,30.0)$ \\
max hsTnt (ng/l) & 189 & $(74,727)$ \\
& $\mathrm{n}$ & $\%$ \\
Sex (male) & 16 & 80 \\
Hypertension & 9 & 45 \\
Diabetes & 4 & 20 \\
High cholesterol & 13 & 65 \\
Familial predisposition for coronary artery disease & 12 & 60 \\
Smoking & & \\
Current & 6 & 30 \\
$\quad$ Previous & 3 & 15 \\
Medical treatment at the time of echocardiography & & \\
Beta blockers & 14 & 70 \\
Calcium channel blockers & 3 & 15 \\
ACE inhibitors/ARB & 13 & 65 \\
Diuretics & 1 & 5 \\
Acetylsalisylic acid & 18 & 90 \\
Clopidrogrel & 11 & 55 \\
Statins & 13 & 65 \\
Diabetes medications & 1 & 5 \\
\hline
\end{tabular}

BMI, body mass index; hsTnt, high-sensitivity troponin T; ACE, angiotensin-converting enzyme; ARB, angiotensin receptor blocker. 


\section{ECG findings}

All patients had sinus rhythm with an average heart rate of $69 \pm$ $16 \mathrm{bpm}$. No conduction defects were observed. The median QRScomplex width was $93[83,104] \mathrm{ms}$. One patient had a pathological Q wave in the LAD territory without concurrent STD or TWI. Nine (45\%) patients had STD and TWI was present in $16(80 \%)$ patients. Three (15\%) patients had neither STD nor TWI in their ECGs at the time of echocardiography. At the regional level, STD was observed in $17 / 60$ (28\%) of the segments and TWI was observed in 28/60 (47\%) of the segments. In 12/60 (12\%) segments, both STD and TWI were present and in $27 / 60$ (45\%) segments, no abnormal findings were observed in the ST segments or the T waves.

Time delays from hospital arrival or the time from symptom onset to treatment were not different according to the presence or absence of STD or TWI. TWI was more prevalent in segments with ischemia (coronary stenosis) according to coronary angiography ( $\mathrm{p}=0.058$ ). The positive predictive values (PPV) of TWI and STD for segments with ischemia were $79 \%$ and $82 \%$, the negative predictive values (NPV) were $47 \%$ and $42 \%$, the sensitivity scores were $56 \%$ and $36 \%$ and the specificity scores were $71 \%$ and $86 \%$, respectively. In the absence of both STD and TWI, the existence of significantly stenosed coronary arteries was significantly less prevalent $(\mathrm{p}=0.017$ ). The PPV to predict a non-ischemic segment was $52 \%$, the NPV was $79 \%$, the sensitivity was $41 \%$ and the specificity was $67 \%$.

\section{Echocardiographic findings}

The echocardiography findings are presented in Table 2. In general, the left ventricle exhibited normal size without overt systolic or diastolic dysfunction. Half of the patients showed no regional changes in contractility and the rest showed hypokinesia in $1.6 \pm 1.3$ segments.

\section{Findings in echocardiography in patients with STD}

Compared to patients without STD, patients with STD had longer isovolumetric relaxation time (IVRT) (142 $\pm 19 \mathrm{~ms}$ vs $114 \pm 25 \mathrm{~ms}$, $\mathrm{p}=0.007)$, lower global early diastolic velocity $\left(\mathrm{e}^{\prime}\right)$ in the speckle tracking echocardiography analysis $(0.83 / \mathrm{s}[0.77,1.02]$ vs $1.08 / \mathrm{s}$ $[0.99,1.21], \mathrm{p}=0.006$ ) and lower values of posterior cyclic variation in the integrated backscatter (pCVIBS) analysis $(8.9 \pm 1.9 \mathrm{~dB}$ vs $12.3 \pm$ $2.9 \mathrm{~dB}, \mathrm{p}=0.043)$. STD showed correlations with diabetes $(\mathrm{r}=0.452$, $\mathrm{p}=0.045)$, smoking $(\mathrm{r}=0.596, \mathrm{p}=0.006)$, $\operatorname{pCVIBS}(\mathrm{r}=0.462, \mathrm{p}=$ $0.040), e^{\prime}(\quad 0.619, p=0.004)$, and global circumferential strain (GCS) in the speckle tracking echocardiography analysis $(\mathrm{r}=0.457, \mathrm{p}=$ $0.049)$ and with IVRT $(\mathrm{r}=0.629, \mathrm{p}=0.003)$. The univariate and multivariable analyses of the factors associated with STD are presented in Table 3. Globally, IVRT and $\mathrm{e}^{\prime}$ were independently associated with the presence of STD. Regional changes showed independent associations with $\mathrm{e}^{\prime}$ and STD.

\section{Findings in echocardiography in patients with TWI}

Compared to patients without TWI, patients with TWI had lower left ventricular ejection fraction (LVEF), ( $57 \pm 6 \%$ vs $71 \pm 4 \%, \mathrm{p}=0.008)$ and lower global systolic strain rate $\left(\mathrm{s}^{\prime}\right)$ in the speckle tracking echocardiography analysis ( $1.09 / \mathrm{s}[1.22,0.98]$ vs $1.31 / \mathrm{s}$ [ 1.67, 1.15], $\mathrm{p}=0.050)$. TWI showed correlations with smoking $(\mathrm{r}=0.452, \mathrm{p}=$ $0.045), \mathrm{s}^{\prime}(\mathrm{r}=0.455, \mathrm{p}=00.044)$ and $\operatorname{LVEF}(\mathrm{r}=0.586, \mathrm{p}=$ 0.007 ). The results of the univariate and multivariable analyses of TWI are presented in Table 4. Globally, TWI was independently associated with $s^{\prime}$ and hypertension. The regional changes were independently associated with circumferential strain. Patients with TWI had lower circumferential strain ( $26.8 \pm 4.4 \%$ vs $29.7 \pm 4.1 \%, \mathrm{p}=0.013$ ).

\section{Cardiac biomarkers}

Cardiac biomarkers were elevated. Upon hospital arrival, the median $\left(\mathrm{Q}_{1}, \mathrm{Q}_{3}\right)$ of the high-sensitivity troponin $\mathrm{T}$ (hsTnt) was $117 \mathrm{ng} / \mathrm{l}(43$, 196) (normal $15 \mathrm{ng} / \mathrm{l}$ ) with a maximum value of $189 \mathrm{ng} / \mathrm{l}(74,727)$ during the hospital stay. Pro-B-type natriuretic peptide (ProBNP) was $1003 \mathrm{ng} / \mathrm{l}(567,1464)$, hemoglobin was $140 \mathrm{ng} / \mathrm{l}(136,151)$, total cholesterol was $4.7 \mathrm{mmol} / \mathrm{l}(4.1,5.7)$, LDL was $3.2 \mathrm{mmol} / \mathrm{l}(2.5,4.0)$ and

Table 2

Echocardiographic results of the study population.

\begin{tabular}{|c|c|c|c|c|c|c|c|c|}
\hline & \multicolumn{2}{|l|}{ All patients } & \multicolumn{3}{|c|}{ Patients with STD } & \multicolumn{3}{|c|}{ Patients with TWI } \\
\hline & \multicolumn{2}{|l|}{$\mathrm{n}=20$} & \multicolumn{3}{|l|}{$\mathrm{n}=9$} & \multicolumn{3}{|l|}{$\mathrm{n}=16$} \\
\hline & Mean/median & $\mathrm{SD} /\left(\mathrm{Q}_{1}, \mathrm{Q}_{3}\right)$ & Mean/median & $\mathrm{SD} /\left(\mathrm{Q}_{1}, \mathrm{Q}_{3}\right)$ & $\mathrm{p}$ & Mean/median & $\mathrm{SD} /\left(\mathrm{Q}_{1}, \mathrm{Q}_{3}\right)$ & $\mathrm{p}$ \\
\hline \multicolumn{9}{|l|}{ Structures } \\
\hline LVEDD & 49.6 & 4.0 & 50.3 & 3.8 & 0.528 & 50.2 & 3.2 & 0.329 \\
\hline LVEDS & 33.6 & 4.3 & 34.2 & 3.6 & 0.628 & 34.5 & 3.2 & 0.051 \\
\hline IVS & 11.3 & $(10.8,11.8)$ & 11.5 & $(10.9,12.0)$ & 0.295 & 11.1 & $(10.8,11.8)$ & 0.682 \\
\hline PW & 11.4 & $(10.7,12.4)$ & 11.4 & $(10.0,12.2)$ & 0.710 & 11.6 & $(10.5,12.4)$ & 0.617 \\
\hline cIBS & 16.5 & 4.1 & 15.4 & 4.8 & 0.884 & 16.1 & 4.0 & 0.871 \\
\hline \multicolumn{9}{|l|}{ Diastolic function } \\
\hline Mitral E-wave & 72 & 21 & 67 & 21 & 0.180 & 70 & 20 & 0.098 \\
\hline Mitral ea-ratio & 0.93 & $(0.85,1.39)$ & 0.90 & $(0.81,0.96)$ & 0.238 & 0.93 & $(0.86,1.43)$ & 0.655 \\
\hline IVRT & 127 & 26 & 142 & 19 & 0.007 & 129 & 28 & 0.277 \\
\hline STE global e' & 1.01 & $(0.86,1.13)$ & 0.83 & $(0.77,1.02)$ & 0.006 & 1.00 & $(0.79,1.14)$ & 0.617 \\
\hline STE global a' & 1.15 & $(0.89,1.33)$ & 1.27 & $(1.09,1.48)$ & 0.331 & 1.10 & $(0.94,1.30)$ & 0.211 \\
\hline \multicolumn{9}{|l|}{ Systolic function } \\
\hline LVEF & 59 & 8 & 58 & 10 & 0.328 & 57 & 6 & 0.008 \\
\hline GLS & 15.4 & 2.4 & 14.8 & 2.6 & 0.136 & 15.2 & 2.2 & 0.524 \\
\hline GCS & 28.4 & 4.3 & 27.3 & 3.6 & 0.123 & 27.9 & 4.6 & 0.322 \\
\hline STE global s' & 1.10 & $(1.21,1.00)$ & 1.12 & $\left(\begin{array}{ll}1.18, & 0.99\end{array}\right)$ & 0.824 & 1.09 & $(\quad 1.22$ & 0.050 \\
\hline sCVIBS & 8.5 & 2.7 & 7.9 & 1.7 & 0.308 & 8.6 & 2.9 & 0.899 \\
\hline pCVIBS & 10.7 & 3.0 & 8.9 & 1.9 & 0.043 & 10.8 & 3.0 & 0.835 \\
\hline WMSI & 1.00 & $(1.00,1.03)$ & 1.00 & $(1.00,1.06)$ & 0.882 & 1.01 & $(1.00,1.03)$ & 0.750 \\
\hline
\end{tabular}

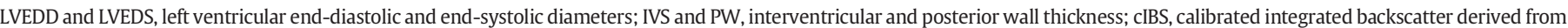

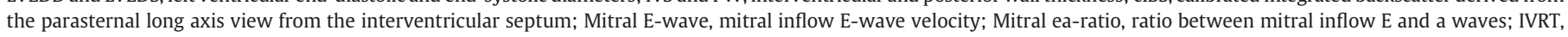

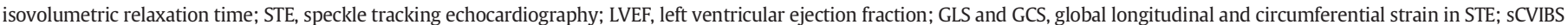

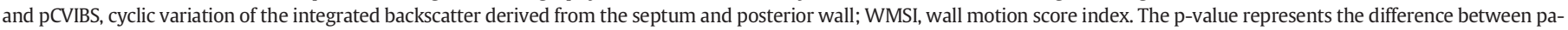
tients with and without changes in STD and TWI.

Bold text indicates statistically significant changes with p 0.05 and text with italics indicates p-value between $0.05-0.10$. 
Table 3

Factors associated with STD

\begin{tabular}{|c|c|c|c|c|c|c|}
\hline & \multicolumn{3}{|c|}{ Univariate analysis } & \multicolumn{3}{|c|}{ Multivariable analysis } \\
\hline & $\beta$ & $\mathrm{SE}(\beta)$ & $\mathrm{p}$ & $\beta$ & $\operatorname{SE}(\beta)$ & $\mathrm{p}$ \\
\hline \multicolumn{7}{|l|}{ Global ST depression } \\
\hline WMSI & 15.044 & 15.763 & 0.340 & & & 0.845 \\
\hline GLS (\%) & 0.325 & 0.219 & 0.138 & & & 0.753 \\
\hline $\begin{array}{l}\text { STE systolic } \\
\text { strain rate }(1 / \mathrm{s})\end{array}$ & 1.436 & 2.341 & 0.540 & & & 0.985 \\
\hline $\begin{array}{l}\text { STE early diastolic } \\
\text { strain rate }(1 / \mathrm{s})\end{array}$ & 9.642 & 4.316 & 0.025 & 1.276 & 0.435 & 0.010 \\
\hline GSC (\%) & 0.188 & 0.125 & 0.133 & & & 0.826 \\
\hline Mitral inflow & 0.036 & 0.027 & 0.189 & & & 0.561 \\
\hline \multicolumn{7}{|l|}{ E-wave $(\mathrm{cm} / \mathrm{s})$} \\
\hline IVRT (ms) & 0.061 & 0.029 & 0.032 & 0.007 & 0.003 & 0.029 \\
\hline $\operatorname{LVEF}(\%)$ & 0.071 & 0.065 & 0.275 & & & 0.888 \\
\hline CVIBS (dB) & 0.254 & 0.258 & 0.324 & & & 0.958 \\
\hline Sex & 0.251 & 1.120 & 0.822 & & & 0.961 \\
\hline Hypertension & 0.875 & 0.931 & 0.347 & & & 0.959 \\
\hline Diabetes & 21.454 & 20096.487 & 0.999 & & & 0.746 \\
\hline High cholesterol & 0.134 & 0.945 & 0.888 & & & 0.987 \\
\hline Age & 0.012 & 0.050 & 0.805 & & & 0.968 \\
\hline Smoking & 1.281 & 1.030 & 0.214 & & & 0.869 \\
\hline \multicolumn{7}{|l|}{ Regional ST depression } \\
\hline WMSI & 3.296 & 6.059 & 0.586 & & & 0.584 \\
\hline $\begin{array}{l}\text { STE longitudinal } \\
\text { strain (\%) }\end{array}$ & 0.057 & 0.04 & 0.158 & & & 0.771 \\
\hline $\begin{array}{l}\text { STE systolic strain } \\
\text { rate }(1 / \mathrm{s})\end{array}$ & 0.355 & 0.960 & 0.727 & & & 0.894 \\
\hline $\begin{array}{l}\text { STE early diastolic } \\
\text { strain rate }(1 / \mathrm{s})\end{array}$ & 5.498 & 1.791 & 0.002 & 5.061 & 2.376 & 0.033 \\
\hline $\begin{array}{l}\text { STE late diastolic } \\
\text { strain rate }(1 / \mathrm{s})\end{array}$ & 0.864 & 0.792 & 0.275 & & & 0.274 \\
\hline $\begin{array}{l}\text { STE circumferential } \\
\text { strain }(\%)\end{array}$ & 0.130 & 0.056 & 0.020 & & & 0.729 \\
\hline CVIBS (dB) & 0.267 & 0.182 & 0.142 & & & 0.103 \\
\hline $\operatorname{clBS}(\mathrm{dB})$ & 0.056 & 0.041 & 0.177 & & & 0.394 \\
\hline Sex & 0.762 & 0.674 & 0.258 & 2.964 & 1.756 & 0.091 \\
\hline Hypertension & 1.318 & 0.648 & 0.042 & 2.992 & 1.554 & 0.054 \\
\hline Diabetes & 20.602 & 11602.713 & 0.999 & & & 0.239 \\
\hline High cholesterol & 0.018 & 0.600 & 0.976 & & & 0.597 \\
\hline Age & 0.017 & 0.032 & 0.593 & & & 0.504 \\
\hline Smoking & 0.711 & 0.604 & 0.239 & & & 0.290 \\
\hline
\end{tabular}

STD, ST-level depression on ECG; WMSI, wall motion score index; GLS and GCS, global longitudinal and circumferential strain; STE, speckle tracking echocardiography; IVRT, isovolumetric relaxation time; LVEF, left ventricular ejection fraction; CVIBS, cyclic variation of the integrated backscatter; cIBS, calibrated integrated backscatter.

Bold text indicates statistically significant changes with p 0.05 and text with italics indicates p-value between $0.05-0.10$.

creatinine was $72 \mu \mathrm{mol} / \mathrm{l}(62,83)$. We found no associations between biomarker values and ECG changes.

\section{Discussion}

In NSTEMI patients, TWIs were associated with changes in systolic function and their locations corresponded with the anatomic distribution of myocardial ischemia. On the other hand, the distribution of STD in the 12 ECG leads did not correlate with the locations of wall motion abnormalities in echocardiography. STD was associated with global and regional changes in diastolic function.

\section{Clinical implications of our findings}

Tissue Doppler imaging and speckle tracking echocardiography have revolutionized the quantitative evaluation of myocardial function. Our study, which utilized these new echocardiographic techniques, provides some new insight into the possible mechanisms behind STD and TWI on the ECG. It is intriguing that STD was associated with diastolic parameter changes and TWI with systolic parameter changes. In NSTEMI, it is evident that these ECG changes are caused by different mechanisms, at least to some extent. First, STD is a robust prognostic factor in non-
Table 4

Factors associated with TWI.

\begin{tabular}{|c|c|c|c|c|c|c|}
\hline & \multicolumn{3}{|c|}{ Univariate analysis } & \multicolumn{3}{|c|}{ Multivariable analysis } \\
\hline & $\beta$ & $\operatorname{SE}(\beta)$ & $\mathrm{p}$ & $\beta$ & $\operatorname{SE}(\beta)$ & $\mathrm{p}$ \\
\hline \multicolumn{7}{|l|}{ Global T-wave inversion } \\
\hline WMSI & & & & & & 0.391 \\
\hline GLS $(\%)$ & 0.168 & 0.252 & 0.504 & & & 0.918 \\
\hline $\begin{array}{l}\text { STE systolic strain } \\
\text { rate }(1 / \mathrm{s})\end{array}$ & 7.517 & 4.215 & 0.075 & 1.002 & 0.314 & 0.006 \\
\hline $\begin{array}{l}\text { STE early diastolic } \\
\text { strain rate }(1 / \mathrm{s})\end{array}$ & 1.928 & 2.865 & 0.501 & & & 0.595 \\
\hline GSC $(\%)$ & 0.159 & 0.161 & 0.324 & & & 0.422 \\
\hline $\begin{array}{l}\text { Mitral inflow E-wave } \\
(\mathrm{cm} / \mathrm{s})\end{array}$ & 0.044 & 0.028 & 0.116 & & & 0.880 \\
\hline IVRT (ms) & 0.028 & 0.025 & 0.273 & & & 0.486 \\
\hline $\operatorname{LVEF}(\%)$ & 0.449 & 0.240 & 0.062 & & & 0.314 \\
\hline CVIBS (dB) & 9.050 & 21.053 & 0.667 & & & 0.498 \\
\hline Sex & 0.368 & 1.320 & 0.781 & & & 0.167 \\
\hline Hypertension & 1.609 & 1.265 & 0.203 & 0.311 & 0.127 & 0.026 \\
\hline Diabetes & 0.368 & 1.320 & 0.781 & & & 0.851 \\
\hline High cholesterol & 0.788 & 1.136 & 0.488 & & & 0.429 \\
\hline Age & 0.094 & 0.075 & 0.211 & & & 0.958 \\
\hline Smoking & 20.287 & 16408.713 & 0.999 & & & 0.648 \\
\hline \multicolumn{7}{|l|}{$\begin{array}{l}\text { Regional T-wave } \\
\text { inversion }\end{array}$} \\
\hline WMSI & 11.236 & 6.981 & 0.108 & & & 0.207 \\
\hline $\begin{array}{l}\text { STE longitudinal } \\
\text { strain }(\%)\end{array}$ & 0.060 & 0.037 & 0.103 & & & 0.160 \\
\hline $\begin{array}{l}\text { STE systolic strain } \\
\text { rate }(1 / \mathrm{s})\end{array}$ & 1.928 & 1.085 & 0.076 & & & 0.136 \\
\hline $\begin{array}{l}\text { STE early diastolic } \\
\text { strain rate }(1 / \mathrm{s})\end{array}$ & 1.651 & 1.142 & 0.148 & & & 0.344 \\
\hline $\begin{array}{l}\text { STE late diastolic } \\
\text { strain rate }(1 / \mathrm{s})\end{array}$ & 0.977 & 0.748 & 0.191 & & & 0.444 \\
\hline $\begin{array}{l}\text { STE circumferential } \\
\text { strain }(\%)\end{array}$ & 0.1340 & 0.051 & 0.007 & 0.132 & 0.061 & 0.032 \\
\hline CVIBS (dB) & 0.090 & 0.116 & 0.440 & & & 0.261 \\
\hline clBS (dB) & 0.032 & 0.036 & 0.380 & & & 0.394 \\
\hline Sex & 0.253 & 0.635 & 0.698 & & & 0.988 \\
\hline Hypertension & 0.713 & 0.530 & 0.179 & & & 0.273 \\
\hline Diabetes & 0.167 & 0.646 & 0.796 & & & 0.262 \\
\hline High cholesterol & 0.059 & 0.542 & 0.914 & & & 0.989 \\
\hline Age & 0.041 & 0.030 & 0.171 & & & 0.239 \\
\hline Smoking & 0.838 & 0.577 & 0.146 & & & 0.313 \\
\hline
\end{tabular}

TWI, T-wave inversion on ECG; WMSI, wall motion score index; GLS and GCS, global longitudinal and circumferential strain; STE, speckle tracking echocardiography; IVRT, isovolumetric relaxation time; LVEF, left ventricular ejection fraction; CVIBS, cyclic variation of the integrated backscatter; cIBS, calibrated integrated backscatter.

Bold text indicates statistically significant changes with p 0.05 and text with italics indicates p-value between $0.05-0.10$.

ST elevation acute coronary syndrome (NSTEMI and unstable angina combined), but the prognostic significance of TWI is controversial [2, 10]. Both the presence and the magnitude of STD and the number of leads with these changes have prognostic impact $[2,11]$. Second, STD is a typical ECG finding during angina pectoris symptoms, while isolated TWI almost never appears during angina pectoris symptoms. Instead, recurrent ischemic symptoms cause "pseudo-normalization" or ST elevations in patients with TWI [12]. Third, TWI, but not STD, tends to be located in the leads that correspond to an ischemic/infarcted region $[2,13]$.

There is clearly a large knowledge gap regarding the possible pathophysiologic mechanisms of STD and TWI in patients with NSTEMI. STD is the hallmark of subendocardial ischemia in patients with stable angina pectoris [4]. Subendocardial MI is a known condition in cardiac imaging, but its association with ECG changes in this context has not been studied in detail [4]. The exploration of the pathophysiological mechanisms behind STD is challenging. In animal experiments, the induction of subendocardial ischemia resulted in a significant increase in the enddiastolic pressure of the left ventricle and loss of left ventricular chamber compliance, indicating diastolic dysfunction $[14,15]$. The fact that STD in our patients was associated with changes in diastolic function parameters is consistent with the experimental hemodynamic data. 
The etiology of TWI in NSTEMI is probably multifactorial. TWI in STEMI patients has been associated with improved outcome related to an open infarct-related artery and restored blood flow [16]. However, TWI has also been associated with non-patency of the culprit artery and worse short-term outcome in late-presenting patients [17]. Interestingly, the results of a recent study with a large number of patients showed that $20 \%$ of the patients presenting with NSTEMI and single-vessel disease had a totally occluded culprit artery [18]. Additionally, cardiac magnetic resonance imaging (CMR) data have shown that approximately $25 \%$ of NSTEMI patient had transmural infarction [19]. Therefore, it can be speculated that MI patients presenting late may have passed the initial stage showing ST elevation and show only "post-ischemic" TWI on the ECG [12]. It is possible that the rapid restoration of normal myocardial function is not achieved in these patients with therapeutic interventions and they may instead develop varying degrees of myocardial edema and stunning [20]. Indeed, in a small study on a sub-type of NSTEMI with TWI - "Wellens' syndrome" - the patients had myocardial edema on cardiac CMR [21]. In addition, repolarization abnormalities on the ECG and myocardial edema had similar time courses. Our study showed an association between TWI and echocardiographic markers of systolic dysfunction on speckle tracking echocardiography analysis. Interestingly, regional echocardiographic changes correlated with the ischemic regions on the ECG.

Tissue Doppler and speckle tracking echocardiography - comparison with previous studies

Data on the clinical roles of the new echocardiographic modalities in coronary artery disease are emerging. Several studies and a recent meta-analysis indicate that speckle tracking echocardiography derived strain is associated with global left ventricular function and has prognostic value in patients with acute STEMI $[22,23]$. However, data on NSTEMI patients are limited. We are not aware of any previous study that has investigated ECG and echocardiography parameters utilizing newer imaging methods. Considering the high rate of NSTEMI patients with a totally occluded culprit artery and the limitations of the ECG to identify this subgroup, it is important to identify these individuals with other diagnostic modalities such as echocardiography [18]. Study results in 40 NSTEMI patients with preserved left ventricular function indicated that speckle tracking echocardiography may be a more sensitive discriminator of left ventricular dyssynchrony than tissue Doppler imaging [24]. In another study including 111 patients with suspected NSTEMI who received echocardiography within $1 \mathrm{~h}$ (median value; interquartile range $0.5-4 \mathrm{~h}$ ) of admittance, $61 \%$ had a clinical diagnosis of NSTEMI, $16 \%$ had a diagnosis of unstable angina, and $23 \%$ had non-coronary chest pain [25]. Territorial systolic strain, measured by averaging all segmental peak systolic strain values in each territory in the 16-segment left ventricular model, proved to be the most reliable method to identify acute total occlusion. A territorial circumferential strain value $\quad 10 \%$ had $90 \%$ sensitivity and $88 \%$ specificity for the identification of a totally occluded culprit artery. Symmetrical TWI was present in $33 \%$ and $31 \%$ of the patients with an occluded and a non-occluded culprit artery, respectively. Our patients had a higher frequency of TWI, but we did not restrict the definition of TWI to symmetrical T waves and in our study, all patients had NSTEMI. In our study, patients with TWI had lower circumferential strain.

\section{Limitations of our study}

Our study has clear limitations. The patient population was small. Therefore, all speculations regarding pathophysiological mechanisms should be considered hypothetical, especially since CMR was not part of the protocol. Additionally, the limited number of patients made it impractical to introduce patients with both STD and TWI as a third group in the statistical analyses.

\section{Conclusion}

In NSTEMI patients with well-preserved global left ventricular systolic function, subtle changes in myocardial imaging were found. STD was associated with changes in diastolic function, and TWI was associated with systolic deterioration. The findings are consistent with the proposed pathophysiologic mechanisms behind these ECG changes.

\section{Disclosure of interest}

The authors state no conflict of interest related to the study.

\section{Funding}

This study was supported by the Paavo and Eila Salonen Legacy, Ida Montin Fund, The Finnish Medical Foundation, The Finnish Cultural Foundation, Pirkanmaa Regional Fund, The Finnish Foundation for Cardiovascular Research, Finnish Society of Oncology, Pirkanmaa Cancer Society, Finnish-Norwegian Medical Foundation, The Pirkanmaa Hospital District, and The Aarne and Aili Turunen Foundation.

\section{Acknowledgements}

The authors thank the research nurses, Virpi Räsänen, Hanna Näppilä and Kati Helleharju, for their expert assistance during the study.

\section{References}

[1] Gregg RE, Babaeizadeh S. Detection of culprit coronary lesion location in pre-hospital 12-lead ECG. J Electrocardiol 2014;47(6):890-4.

[2] Atar S, Fu Y, Wagner GS, Rosanio S, Barbagelata A, Birnbaum Y. Usefulness of ST depression with T-wave inversion in leads $V(4)$ to $V(6)$ for predicting one-year mortality in non-ST-elevation acute coronary syndrome (from the Electrocardiographic Analysis of the Global Use of Strategies to Open Occluded Coronary Arteries IIB Trial). Am J Cardiol 2007:99(7):934-8.

[3] Birnbaum Y, Nikus K, Kligfield P, Fiol M, Barrabes JA, Sionis A, et al. The role of the ECG in diagnosis, risk estimation, and catheterization laboratory activation in patients with acute coronary syndromes: a consensus document. Ann Noninvasive Electrocardiol 2014;19(5):412-25.

[4] Ishida M, Kato S, Sakuma H. Cardiac MRI in ischemic heart disease. Circ J 2009;73(9): 1577-88.

[5] Leischik R, Dworrak B, Sanchis-Gomar F, Lucia A, Buck T, Erbel R. Echocardiographic assessment of myocardial ischemia. Ann Transl Med 2016;4(13):259.

[6] Smiseth OA, Torp H, Opdahl A, Haugaa KH, Urheim S. Myocardial strain imaging: how useful is it in clinical decision making? Eur Heart J 2016;37(15):1196-207.

[7] Thygesen K, Alpert JS, Jaffe AS, Simoons ML, Chaitman BR, White HD, et al. Third universal definition of myocardial infarction. Circulation 2012;126(16):2020-35.

[8] Roffi M, Patrono C, Collet JP, Mueller C, Valgimigli M, Andreotti F, et al. 2015 ESC Guidelines for the management of acute coronary syndromes in patients presenting without persistent ST-segment elevation: Task Force for the Management of Acute Coronary Syndromes in Patients Presenting without Persistent ST-Segment Elevation of the European Society of Cardiology (ESC). Eur Heart J 2016;37(3):267-315.

[9] Lang RM, Bierig M, Devereux RB, Flachskampf FA, Foster E, Pellikka PA, et al. Recommendations for chamber quantification: a report from the American Society of Echocardiography's Guidelines and Standards Committee and the Chamber Quantification Writing Group, developed in conjunction with the European Association of Echocardiography, a branch of the European Society of Cardiology. J Am Soc Echocardiogr 2005;18(12):1440-63.

[10] Mueller C, Neumann FJ, Perach W, Perruchoud AP, Buettner HJ. Prognostic value of the admission electrocardiogram in patients with unstable angina/non-STsegment elevation myocardial infarction treated with very early revascularization. Am J Med 2004:117(3):145-50.

[11] Barrabes JA, Figueras J, Moure C, Cortadellas J, Soler-Soler J. Prognostic significance of ST segment depression in lateral leads I, aVL, V5 and V6 on the admission electrocardiogram in patients with a first acute myocardial infarction without ST segment elevation. J Am Coll Cardiol 2000;35(7):1813-9.

[12] Nikus K, Pahlm O, Wagner G, Birnbaum Y, Cinca J, Clemmensen P, et al. Electrocardiographic classification of acute coronary syndromes: a review by a committee of the International Society for Holter and non-invasive electrocardiology. J Electrocardiol 2010;43(2):91-103.

[13] de Luna AB, Zareba W, Fiol M, Nikus K, Birnbaum Y, Baranowski R, et al. Negative T wave in ischemic heart disease: a consensus article. Ann Noninvasive Electrocardiol 2014;19(5):426-41.

[14] Palacios I, Johnson RA, Newell JB, Powell Jr WJ. Left ventricular end-diastolic pressure volume relationships with experimental acute global ischemia. Circulation 1976; 53(3):428-36 
[15] Guyton RA, McClenathan JH, Newman GE, Michaelis LL. Significance of subendocardial S-T segment elevation caused by coronary stenosis in the dog. Epicardial S-T segment depression, local ischemia and subsequent necrosis. Am J Cardiol 1977; 40(3):373-80.

[16] Doevendans PA, Gorgels AP, van der Zee R, Partouns J, Bar FW, Wellens HJ. Electrocardiographic diagnosis of reperfusion during thrombolytic therapy in acute myocardial infarction. Am J Cardiol 1995;75(17):1206-10.

[17] Herz I, Birnbaum Y, Zlotikamien B, Strasberg B, Sclarovsky S, Chetrit A, et al. The prognostic implications of negative T waves in the leads with ST segment elevation on admission in acute myocardial infarction. Cardiology 1999;92(2):121-7.

[18] Warren J, Mehran R, Yu J, Xu K, Bertrand ME, Cox DA, et al. Incidence and impact of totally occluded culprit coronary arteries in patients presenting with non-STsegment elevation myocardial infarction. Am J Cardiol 2015;115(4):428-33.

[19] Sarafoff N, Schuster T, Vochem R, Fichtner S, Martinoff S, Schwaiger M, et al. Association of ST-elevation and non-ST-elevation presentation on ECG with transmurality and size of myocardial infarction as assessed by contrast-enhanced magnetic resonance imaging. J Electrocardiol 2013;46(2):100-6.

[20] Mewton N, Bonnefoy E, Revel D, Ovize M, Kirkorian G, Croisille P. Presence and extent of cardiac magnetic resonance microvascular obstruction in reperfused
non-ST-elevated myocardial infarction and correlation with infarct size and myocardial enzyme release. Cardiology 2009;113(1):50-8.

[21] Migliore F, Zorzi A, Marra MP, Basso C, Corbetti F, De Lazzari M, et al. Myocardial edema underlies dynamic T-wave inversion (Wellens' ECG pattern) in patients with reversible left ventricular dysfunction. Heart Rhythm 2011;8(10):1629-34.

[22] Orii M, Hirata K, Tanimoto T, Shiono Y, Shimamura K, Ishibashi K, et al. Twodimensional speckle tracking echocardiography for the prediction of reversible myocardial dysfunction after acute myocardial infarction: comparison with magnetic resonance imaging. Echocardiography 2015;32(5):768-78.

[23] Shetye A, Nazir SA, Squire IB, McCann GP. Global myocardial strain assessment by different imaging modalities to predict outcomes after ST-elevation myocardial infarction: a systematic review. World J Cardiol 2015;7(12):948-60.

[24] Ng AC, Tran da T, Newman M, Allman C, Vidaic J, Leung DY. Comparison of left ventricular dyssynchrony by two-dimensional speckle tracking versus tissue Doppler imaging in patients with non-ST-elevation myocardial infarction and preserved left ventricular systolic function. Am J Cardiol 2008;102(9):1146-50.

[25] Grenne B, Eek C, Sjoli B, Dahlslett T, Uchto M, Hol PK, et al. Acute coronary occlusion in non-ST-elevation acute coronary syndrome: outcome and early identification by strain echocardiography. Heart 2010;96(19):1550-6. 